\title{
FORMATION OF HUMBOLDTINE DURING THE DISSOLUTION OF HEMATITE IN OXALIC ACID - DENSITY FUNCTIONAL THEORY (DFT) CALCULATIONS AND EXPERIMENTAL VERIFICATION
}

\author{
Paula Vehmaanperä ${ }^{1} *$ (D) Bo Gong ${ }^{2,3},{\text { Patrick H.-L. } \text { Sit }^{2} \text {, Rina Salmimies }}^{4}$, \\ Bernardo BarbiellinI ${ }^{5,6}$, AND ANTti HäKKINEN ${ }^{1}$ \\ ${ }^{1}$ Department of Separation Science, School of Engineering Science, LUT University, FI-53851 Lappeenranta, Finland \\ ${ }^{2}$ School of Energy and Environment, City University of Hong Kong, Kowloon, Hong Kong, Special Administrative Region, China \\ ${ }^{3}$ Department of Environmental Science and Engineering, University of Science and Technology of China, Hefei 230026, China \\ ${ }^{4}$ School of Engineering Science, LUT University, FI-53851 Lappeenranta, Finland \\ ${ }^{5}$ Department of Physics, School of Engineering Science, LUT University, FI-53851 Lappeenranta, Finland \\ ${ }^{6}$ Department of Physics, Northeastern University, Boston, MA 02115, USA
}

\begin{abstract}
Understanding the reactions taking place in the hematite-oxalic acid system is important in order to clean iron oxides from filters and to remove iron from mineral concentrates. Previous studies reported the formation of an unwanted solid phase during this process. The objective of the current work, therefore, was to visualize and rationalize the iron dissolution steps taking place in the hematite-oxalic acid reaction by combining density functional theory (DFT) calculations and experimental data. The results of DFT calculations indicated that a precipitate was formed in this reaction; XRD analysis of the solid phase after the dissolution experiment revealed the formation of humboldtine as the precipitate. The attachment of oxalate on the hematite surface and the reduction of Fe(III) to $\mathrm{Fe}$ (II) were key steps for humboldtine formation. Both simulations and the experimental results showed that greater oxalic acid concentrations yielded more precipitate, suggesting a simple and novel route to synthesize humboldtine, a material which is relevant to the demand for clean energy.
\end{abstract}

Keywords_-Density Functional Theory $\cdot$ Hematite $\cdot$ Humboldtine $\cdot$ Iron dissolution $\cdot$ Oxalates $\cdot$ XRD analysis

\section{INTRODUCTION}

Reactions at a solid-liquid interphase play a vital role in understanding a dissolution phenomenon. Recent research efforts have helped to improve dissolution-based processes such as the regeneration of ceramic filter media (Salmimies et al., 2013; Smith et al., 2018) and leaching iron from clays (Mandal $\&$ Banerjee, 2004). Sulfuric and nitric acid are commonly used leaching agents for iron oxides, but more effective dissolution can be achieved using a solution that contains complexing ligands. Complexing agents such as ethylenediaminetetraacetic acid (EDTA), trisodium nitrilotriacetate (NTA), hydroxyethylethylenediaminetriacetic acid (HEDTA), pentetic acid (DTPA), and methanesulfonic acid (MSA) have been used to enhance the dissolution of iron oxides (Chang \& Matijevic, 1983; Blesa et al., 1984; Wang et al., 2017). Among these ligands, oxalic acid has also received a lot of attention as it can dissociate into strong complexing oxalate ions for the dissolution (Cornell \& Schindler, 1987; Panias et al., 1996; Lee et al., 2007; Salmimies et al., 2016). Oxalic acid was chosen for the present study because it is environmentally friendly. Moreover, it can also dissolve aluminum and manganese, which are often

* E-mail address of corresponding author: paula. vehmaanpera@lut.fi

DOI: $10.1007 / \mathrm{s} 42860-021-00146-5$ also present in clay minerals (Rennert et al., 2021).

The reaction scheme for dissolution of hematite in oxalic acid can be described via Eqs. 1-10 (Stumm \& Furrer, 1987; Siffert \& Sulzenberger, 1991; Panias et al., 1996).

Dissociation of oxalic acid:

$\mathrm{H}_{2} \mathrm{C}_{2} \mathrm{O}_{4} \leftrightarrow \mathrm{HC}_{2} \mathrm{O}_{4}^{-}+\mathrm{H}^{+}$

$\mathrm{HC}_{2} \mathrm{O}_{4}^{-} \leftrightarrow \mathrm{C}_{2} \mathrm{O}_{4}^{2-}+\mathrm{H}^{+}$

Surface protonation:

$>\mathrm{Fe}(\mathrm{III})-\mathrm{O}+\mathrm{H}^{+} \leftrightarrow>\mathrm{Fe}(\mathrm{III})-\mathrm{OH}^{+}$

Surface complexation:

$$
\begin{aligned}
> & \mathrm{Fe}(\mathrm{III})-\mathrm{OH}^{+}+\mathrm{L}^{n-}+\mathrm{H}^{+} \leftrightarrow[>\mathrm{Fe}(\mathrm{III})-\mathrm{L}]^{(n-2)-} \\
& +\mathrm{H}_{2} \mathrm{O}
\end{aligned}
$$

Electron transfer from ox to $\mathrm{Fe}(\mathrm{III})$ and detachment of $\mathrm{Fe}(\mathrm{II})$

$[>\mathrm{Fe}(\mathrm{III})-\mathrm{ox}] \leftrightarrow[>\mathrm{Fe}(\mathrm{II})-\mathrm{ox}]$

$2[\mathrm{Fe}(\mathrm{II})-\mathrm{ox}]+2 \mathrm{H}^{+} \rightarrow 2 \mathrm{Fe}_{(\mathrm{aq})}^{2+}+2 \mathrm{CO}_{2}+\mathrm{ox}+2>\mathrm{H}(6)$ 
Autocatalytic dissolution:

$$
\begin{gathered}
{[>\mathrm{Fe}(\mathrm{III})-\mathrm{ox}]+\left[\mathrm{Fe}^{2+}-\mathrm{ox}\right]_{(\mathrm{aq})} \rightarrow} \\
>\mathrm{Fe}(\mathrm{III})-\mathrm{ox} . . \mathrm{Fe}^{2+}-\mathrm{ox}
\end{gathered}
$$

$$
\begin{gathered}
>\mathrm{Fe}(\mathrm{III})-\mathrm{ox} . . . \mathrm{Fe}^{2+}-\mathrm{ox} \rightarrow \\
>\mathrm{Fe}(\mathrm{II})-\text { ox....Fe } \mathrm{Fe}^{3+}-\text { ox }
\end{gathered}
$$

$$
\begin{aligned}
> & \mathrm{Fe}(\mathrm{II})-\mathrm{ox} . . . \mathrm{Fe}^{3+}-\mathrm{ox} \rightarrow \\
& >\mathrm{Fe}(\mathrm{II})-\mathrm{ox}+\left[\mathrm{Fe}^{3+} \mathrm{ox}\right]_{(\mathrm{aq})}
\end{aligned}
$$

$$
>\mathrm{Fe}(\mathrm{II})-\mathrm{ox} \rightarrow\left[\mathrm{Fe}^{2+}-\mathrm{ox}\right]_{(\mathrm{aq})}
$$

Symbol '>' describes the solid surface, $\mathrm{L}$ is the ligand, II or III is the oxidation state of iron in the solid phase, $2+$ or $3+$ is the oxidation state of iron in the liquid, '...' is the adsorbed species on the solid surface, and ox refers to species formed from oxalic acid, i.e. $\mathrm{HC}_{2} \mathrm{O}_{4}{ }^{-}$or $\mathrm{C}_{2} \mathrm{O}_{4}{ }^{-}$

In previous studies (Lee et al., 2007; Salmimies et al., 2016), the formation of a solid precipitate was observed during the dissolution of hematite in oxalic acid. This reaction product, however, was not considered in the original reaction scheme (Eqs. 1-10). Often, solid precipitation is a drawback that hinders the dissolution process, blocks the filter media, or reduces the whiteness of the clay mineral, which cannot then be used again as a raw material in the ceramics industry. This precipitate is humboldtine, named after Friedrich Wilhelm Heinrich Alexander von Humboldt (1769-1859), naturalist, explorer, and scientist. The formation of humboldtine can be described by Eq. 11, which can take place after the reduction of surface $\mathrm{Fe}$ (III) to $\mathrm{Fe}$ (II) (Eq. 5).

$\mathrm{Fe}(\mathrm{II})+\mathrm{C}_{2} \mathrm{O}_{4}^{2-}+2 \cdot \mathrm{H}_{2} \mathrm{O} \rightarrow \mathrm{Fe}(\mathrm{II})\left(\mathrm{C}_{2} \mathrm{O}_{4}\right) \cdot 2 \mathrm{H}_{2} \mathrm{O}_{(\mathrm{s})}$

The thermal decomposition of humboldtine reverses this reaction by restoring both magnetite (Angermann \& Töpfer, 2008) and hematite (Ogasawara \& Koga, 2014). Such thermal decomposition may also occur on Mars (Applin et al., 2015). The formation of humboldtine is of great interest because, though it can have drawbacks in terms of dissolution, its use has recently been demonstrated for high conductivity (Yamada et al., 2009; Huskić et al., 2016; Yao et al., 2019) and for photocatalysis (Fan et al., 2016), and thus its facile synthesis has become a relevant research topic (Müller et al., 2021). The conditions under which humboldtine is formed in nature remain unknown (Robinson, 2004), but formation has been observed when pyrite rocks are in contact with oxalic acid (Green, 2004). Moreover, the formation of humboldtine has also been associated with oxalic acid produced by microorganisms near iron surfaces (Aramendia et al., 2015). Clearly, the formation of humboldtine in nature is dependent on the iron composition of the rock substrate (Gadd et al., 2014). Very often humboldtine is synthesized via several steps (Müller et al., 2021) whereas the formation of humboldtine via dissolution-precipitation reaction under mild conditions (at the temperature of $35^{\circ} \mathrm{C}$ ) could offer a simpler route. Understanding the mechanism causing humboldtine formation under dissolution conditions is, therefore, important. The reaction steps shown in Eqs. 1-10 are, thus, hypothetical. DFT calculations offer a unique window to visualize the actual mechanisms taking place during the dissolution, and such calculations have already been deployed successfully to study the hematite surface (Huang et al., 2016; Si et al., 2020) and a hematite and benzene system (Dzade et al., 2014).

The aim of the current study, therefore, was to examine the conditions and mechanisms leading to the formation of humboldtine via dissolution of hematite in oxalic acid, with emphasis on the DFT calculations combined with experimental verification. A further objective was to verify the formation of humboldtine in the specific acid system being studied here. The hypothesis was that the DFT calculations would define the actual dissolution mechanisms taking place in the system and provide understanding of the adsorption, electron-transfer, and precipitation processes.

\section{MATERIALS AND METHODS}

\section{Computational Methodology}

$\alpha-\mathrm{Fe}_{2} \mathrm{O}_{3}$ with lattice parameters $a=b=5.036 \AA, c=13.75 \AA$, $\alpha=\beta=90^{\circ}$, and $\gamma=120^{\circ}$ was used here, consistent with previous experimental work (Blake et al., 1966). The (0001) surface with a $2 \times 2$ supercell and the nine-layer periodic slab model was constructed. A $>12 \AA$ vacuum length was set in the $z$ direction to avoid interactions between the periodic images. The surface was optimized with the atoms on the uppermost four layers allowed to relax. The adsorption energies $\left(E_{\text {ads }}\right)$ were calculated with the equation: $E_{\text {ads }}=E_{\text {complex }}-\left(E_{\text {molecule }}+E_{\text {surface }}\right)$, where $E_{\text {complex }}$, $E_{\text {molecule }}$, and $E_{\text {surface }}$ represent the total energy of the complex after adsorption, the energy of the free molecule (e.g. $\mathrm{H}_{2} \mathrm{C}_{2} \mathrm{O}_{4}$, $\mathrm{H}_{2} \mathrm{O}$ ), and energy of the free surface, respectively. The free molecules were also optimized with the same parameters as used for the surface. The Bader charges for all configurations were calculated for the analysis of the electron-transfer processes (Henkelman et al., 2006). In the Bader charge-analysis scheme, the simulation system was partitioned into different volumes by the surfaces of minimum electronic density. The electronic density within one volume is then assigned to the atom in that volume. The Bader charge analysis scheme is a powerful tool which allows the change in the atomic charges during the reaction to be analyzed. Furthermore, the oxidation state-determination method to examine the changes in the oxidation states of Fe during the reaction (Sit et al., 2011) was also adopted. In this method, a $5 \times 5$ occupation matrix was constructed for each electron spin by projecting the Kohn-Sham wave functions from the DFT calculations onto the atomic $\mathrm{d}$ orbitals of the transition metal ion. The eigenvalues of the matrix are called the occupation numbers. As shown earlier (Sit et al., 2011), the occupation numbers close to 
unity correspond to the $\mathrm{d}$ electrons belonging to the ion. The oxidation state can then be assigned with knowledge of the number of $\mathrm{d}$ electrons in the ion. The method has been applied successfully to study the oxidation states of transition metal ions in various problems (Sit et al., 2012; Majumdar et al., 2017; Wei et al., 2017; Ku and Sit, 2019; Ricca et al., 2019; Wang et al., 2019; Jensen et al., 2020). Further details of this method can be found in Sit et al. (2011). All the DFT calculations were performed using the PWscf module of the Quantum Espresso (QE) package (Giannozzi et al., 2009). The generalized gradient approximation (GGA) proposed by Perdew, Burke, and Ernzerh (PBE) was used to describe the exchange correlation energy (Perdew et al., 1996). The ultrasoft pseudopotentials were used to simulate electron-ionic core interactions (Vanderbilt, 1990). The van der Waals interaction correction with the DFT-D2 scheme proposed by Grimme (2006) was used to simulate the weak interactions. The cutoff energies were set equally for all the calculations, which were 30 Rydberg $(408 \mathrm{eV})$ and 240 Rydberg $(3265 \mathrm{eV})$ for the wavefunctions and the augmented part of the charge density, respectively. The $2 \times 2 \times 1$ Monkhorst-Pack k-point mesh was found to be adequate in this study after testing. Spinpolarized calculations were carried out for the systems involving $\alpha-\mathrm{Fe}_{2} \mathrm{O}_{3}$ because $\alpha-\mathrm{Fe}_{2} \mathrm{O}_{3}$ has unpaired electrons. Also, the Hubbard $\mathrm{U}$ value was set to $5 \mathrm{eV}$ to consider accurately the strongly correlated d electrons (Dzade et al., 2014). Constrained optimization simulations were carried out to calculate the activation barrier of the $\mathrm{C}-\mathrm{C}$ bond of the $\mathrm{H}_{2} \mathrm{C}_{2} \mathrm{O}_{4}$.

\section{Materials}

Analytical-grade oxalic dihydrate powder from Merck (99\%, Darmstadt, Germany) and Millipore-water were used to prepare $0.33 \mathrm{M}$ oxalic acid solution for the dissolution experiment. The solid synthetic hematite powder was from Alfa Aesar (98\%, Kandel, Germany). Analytical-grade, concentrated nitric acid from Merck (65\%, Darmstadt, Germany) was used for the preparation of the nitric acid solution for the Fe concentration analysis.

\section{Dissolution Experiment}

The dissolution experiment followed a similar set-up as in the previous studies of the authors (Salmimies et al., 2016; Vehmaanperä et al., 2021). The experiment was done in a $1 \mathrm{~L}$ water-jacketed glass reactor, which was equipped with a Lauda Proline RP855 thermostat to keep the reaction temperature constant. The system was equilibrated with air and the experiment was done under light. A pitched-blade turbine with a mixing speed of $800 \mathrm{rpm}$ and four baffles ensured effective mixing. The experiment was run in the following manner: (1) oxalic acid solution was heated to $35^{\circ} \mathrm{C}$; (2) $12 \mathrm{~g}$ of hematite powder was added to the reactor; and (3) mixing was switched on. Solution samples were collected from the reactor with a syringe, filtered using a $0.22 \mu \mathrm{m}$ syringe filter, and diluted with 14 wt.\% nitric acid to avoid any changes in the samples before analysis.

The slurry was collected after the experiment and filtered using a Büchner funnel equipped with a Whatman ${ }^{\circledR} 42$ filter paper. After this, the solids were dried in an oven at $40^{\circ} \mathrm{C}$. According to Schwertmann \& Cornell (2003), this temperature is low enough to avoid any phase modification or transformation caused by oven drying. After drying, the solids were ground gently in a mortar before XRD and SEM-EDS analysis.

Equilibrium was reached within $413 \mathrm{~h}$, but the solubility data are not reported here because the present investigation was of the formation of humboldtine using DFT with experimental verification. Experimental data and discussion of the kinetics and equilibrium of dissolution of iron oxides collected with the described set-up have been reported elsewhere (Salmimies et al., 2016; Vehmaanperä et al. 2021).

\section{Analysis}

The $\mathrm{pH}$ of solutions from the reactor was measured using a WTW pH 401 i-meter with a WTW SenTix 41 electrode (Xylem Analytics, Weinheim, Germany). The $\mathrm{pH}$ ranged from 0.8 to 1.0 during the dissolution, which was favorable for the formation of humboldtine (Lee et al., 2007). The concentration of total dissolved $\mathrm{Fe}$ was determined using a flame atomic absorption spectrometer (Thermo Scientific iCE 3000 AAS with a detection limit of $0.02 \mathrm{mg} / \mathrm{L}$ for Fe, China).

The mineralogical composition of the residual solid was analyzed using X-ray diffraction (XRD, Bruker D8 Focus with $\mathrm{CuK} \alpha$ radiation, Karlsruhe, Germany). The XRD data were recorded from 10 to $70^{\circ} 2 \theta$ with a step size of $0.02^{\circ} 2 \theta$ and a scanning speed of $0.02^{\circ} 2 \theta \mathrm{s}^{-1}$. The phase identification was done using the DIFFRAC.EVA software and the PDF 4 database. A scanning electron microscope (SEM, Hitachi SU 3500 with Thermo Scientific, UltraDry SDD EDS, Madison, Wisconsin, USA) was used to estimate the elemental composition and morphology of the solids.

\section{RESULTS}

\section{DFT Calculations}

As in the paper by Dzade et al. (2014), the present study considered the (0001) surface of hematite because it is the dominant surface obtained under most conditions (Parkinson, 2016). The adsorption of oxalic acid onto the $\mathrm{Fe}_{2} \mathrm{O}_{3}$ surface and the charge transfer were studied using Bader charge analysis and oxidation state determination. For oxalic acid adsorption, spontaneous proton transfer from the oxalic acid to the surface took place. Therefore, only stable structures for singly de-protonated and oxalate adsorption could be obtained. For both cases, electron transfer from the molecule to the surface was observed (Table 1), suggesting that the molecule was oxidized partially upon adsorption. Oxalate adsorption was stronger than singly de-protonated adsorption, and it also showed a larger electron transfer.

A main objective of the DFT study was to understand the adsorption and the electron-transfer processes. In the charge analysis, although oxalate was oxidized, the reduction of the surface Fe was not very significant. A possible reason is that the electron from the oxalate was shared by the whole $\mathrm{Fe}_{2} \mathrm{O}_{3}$ 
Table 1 Bader charges of the adsorbed singly de-protonated $\left(\mathrm{HC}_{2} \mathrm{O}_{4}^{-}\right)$and doubly de-protonated $\left(\mathrm{C}_{2} \mathrm{O}_{4}{ }^{2-}\right)$ species and the top-surface $\mathrm{Fe}$ with the Hubbard $\mathrm{U}$ of $5 \mathrm{eV}$

\begin{tabular}{lll}
\hline & Before adsorption & After adsorption \\
\hline $\mathrm{HC}_{2} \mathrm{O}_{4}^{-}$ & -1 & -0.76 \\
$\mathrm{Fe}_{(1)}$ & 1.61 & 1.62 \\
$\mathrm{Fe}_{(2)}$ & 1.61 & 1.70 \\
$\mathrm{Fe}_{(3)}$ & 1.61 & 1.70 \\
$\mathrm{Fe}_{(4)}$ & 1.61 & 1.62 \\
$\mathrm{C}_{2} \mathrm{O}_{4}{ }^{2-}$ & -2 & -1.44 \\
$\mathrm{Fe}_{(1)}$ & 1.61 & 1.64 \\
$\mathrm{Fe}_{(2)}$ & 1.61 & 1.73 \\
$\mathrm{Fe}_{(3)}$ & 1.61 & 1.73 \\
$\mathrm{Fe}_{(4)}$ & 1.61 & 1.63 \\
\hline
\end{tabular}

slab instead of reducing a particular Fe. This fact was also confirmed by Stone and Morgan (1987). Clearly, the reduction of Fe did not occur during adsorption as supported by the oxidation states of the Fe (Table 2).

When the $\mathrm{C}-\mathrm{C}$ bond broke, reduction of two surface $\mathrm{Fe}$ atoms from $\mathrm{Fe}$ (III) to $\mathrm{Fe}$ (II) was noted. The oxidation state calculations method through DFT calculations allowed assignment of $\mathrm{d}$ electrons to various Fe ions, and thus to extract their oxidation states. The present analysis indicated that the reaction proceeded first as the reduction of surface $\mathrm{Fe}$ (III) to $\mathrm{Fe}$ (II) by the $\mathrm{C}_{2} \mathrm{O}_{4}{ }^{2-} \rightarrow 2 \mathrm{CO}_{2}$ reaction. Then the remaining oxalate reacted with the surface $\mathrm{Fe}$ (II) to form humboldtine. The top view and side view of the structure after the $\mathrm{C}-\mathrm{C}$ bond was broken with four representative Fe positions are shown in Fig. 1. The DFT results revealed specific locations on the surface, namely, $\mathrm{Fe}_{(1)}$ and $\mathrm{Fe}_{(2)}$, that were the most favorable sites for initiating the formation of the precipitate.

Table 2 Bader charges and oxidation-state analysis for the top-surface Fe before oxalic acid adsorption, after oxalic acid adsorption, and after the $\mathrm{C}-\mathrm{C}$ bond of the oxalate breaks. The occupation numbers taken as full occupation are in bold. These are the d electrons assigned to the $\mathrm{Fe}$ ions

\begin{tabular}{|c|c|c|c|c|c|c|c|c|}
\hline & Bader charge & \multicolumn{6}{|c|}{ Occupation numbers } & Oxidation state \\
\hline \multicolumn{9}{|c|}{ Free surface before $\mathrm{H}_{2} \mathrm{C}_{2} \mathrm{O}_{4}$ adsorption (the four $\mathrm{Fe}$ atoms are equivalent) } \\
\hline \multirow{2}{*}{$\mathrm{Fe}$} & 1.61 & Spin up & 0.989 & 0.989 & 0.990 & 0.996 & 0.996 & $\mathrm{Fe}(\mathrm{III})$ \\
\hline & & Spin down & 0.102 & 0.218 & 0.218 & 0.424 & 0.424 & \\
\hline \multicolumn{9}{|c|}{ After singly de-protonated $\mathrm{H}_{2} \mathrm{C}_{2} \mathrm{O}_{4}$ adsorption $\left(\mathrm{H}_{2} \mathrm{C}_{2} \mathrm{O}_{4}\right.$ breaks into one $\mathrm{H}^{+}$and one $\left.\mathrm{HC}_{2} \mathrm{O}_{4}^{-}\right)$} \\
\hline \multirow[t]{2}{*}{$\mathrm{Fe}_{(1)}$} & 1.62 & Spin up & 0.989 & 0.990 & 0.991 & 0.996 & 0.996 & $\mathrm{Fe}(\mathrm{III})$ \\
\hline & & Spin down & 0.104 & 0.213 & 0.223 & 0.420 & 0.423 & \\
\hline \multirow[t]{2}{*}{$\mathrm{Fe}_{(2)}$} & 1.70 & Spin up & 0.990 & 0.990 & 0.994 & 0.995 & 0.995 & $\mathrm{Fe}(\mathrm{III})$ \\
\hline & & Spin down & 0.164 & 0.197 & 0.221 & 0.383 & 0.390 & \\
\hline \multirow[t]{2}{*}{$\mathrm{Fe}_{(3)}$} & 1.70 & Spin up & 0.989 & 0.991 & 0.994 & 0.995 & 0.996 & $\mathrm{Fe}(\mathrm{III})$ \\
\hline & & Spin down & 0.089 & 0.220 & 0.254 & 0.345 & 0.416 & \\
\hline \multirow[t]{2}{*}{$\mathrm{Fe}_{(4)}$} & 1.62 & Spin up & 0.989 & 0.989 & 0.990 & 0.996 & 0.996 & $\mathrm{Fe}(\mathrm{III})$ \\
\hline & & Spin down & 0.101 & 0.212 & 0.219 & 0.420 & 0.426 & \\
\hline \multicolumn{9}{|c|}{ After doubly de-protonated $\mathrm{H}_{2} \mathrm{C}_{2} \mathrm{O}_{4}$ adsorption $\left(\mathrm{H}_{2} \mathrm{C}_{2} \mathrm{O}_{4}\right.$ breaks into two $\mathrm{H}^{+}$and one $\left.\mathrm{C}_{2} \mathrm{O}_{4}{ }^{2-}\right)$} \\
\hline \multirow[t]{2}{*}{$\mathrm{Fe}_{(1)}$} & 1.64 & Spin up & 0.989 & 0.990 & 0.991 & 0.995 & 0.996 & $\mathrm{Fe}(\mathrm{III})$ \\
\hline & & Spin down & 0.107 & 0.212 & 0.224 & 0.414 & 0.418 & \\
\hline \multirow[t]{2}{*}{$\mathrm{Fe}_{(2)}$} & 1.73 & Spin up & 0.989 & 0.990 & 0.992 & 0.995 & 0.995 & $\mathrm{Fe}(\mathrm{III})$ \\
\hline & & Spin down & 0.152 & 0.180 & 0.273 & 0.355 & 0.372 & \\
\hline \multirow[t]{2}{*}{$\mathrm{Fe}_{(3)}$} & 1.73 & Spin up & 0.989 & 0.992 & 0.993 & 0.995 & 0.996 & $\mathrm{Fe}(\mathrm{III})$ \\
\hline & & Spin down & 0.109 & 0.196 & 0.281 & 0.313 & 0.410 & \\
\hline \multirow[t]{2}{*}{$\mathrm{Fe}_{(4)}$} & 1.63 & Spin up & 0.988 & 0.991 & 0.993 & 0.995 & 0.996 & $\mathrm{Fe}(\mathrm{III})$ \\
\hline & & Spin down & 0.085 & 0.121 & 0.303 & 0.408 & 0.426 & \\
\hline \multicolumn{9}{|c|}{ After the $\mathrm{C}-\mathrm{C}$ bond of the adsorbed $\mathrm{C}_{2} \mathrm{O}_{4}{ }^{2-}$ breaks } \\
\hline \multirow[t]{2}{*}{$\mathrm{Fe}_{(1)}$} & 1.64 & Spin up & 0.989 & 0.990 & 0.992 & 0.996 & 0.996 & $\mathrm{Fe}(\mathrm{III})$ \\
\hline & & Spin down & 0.128 & 0.192 & 0.232 & 0.416 & 0.424 & \\
\hline \multirow[t]{2}{*}{$\mathrm{Fe}_{(2)}$} & 1.65 & Spin up & 0.989 & 0.990 & 0.992 & 0.996 & 0.996 & $\mathrm{Fe}(\mathrm{III})$ \\
\hline & & Spin down & 0.133 & 0.197 & 0.229 & 0.412 & 0.421 & \\
\hline \multirow[t]{2}{*}{$\mathrm{Fe}_{(3)}$} & 1.31 & Spin up & 0.985 & 0.991 & 0.993 & 0.997 & 0.998 & $\mathrm{Fe}(\mathrm{II})$ \\
\hline & & Spin down & 0.043 & 0.088 & 0.199 & 0.225 & 0.961 & \\
\hline \multirow[t]{2}{*}{$\mathrm{Fe}_{(4)}$} & 1.38 & Spin up & 0.987 & 0.990 & 0.993 & 0.997 & 0.998 & $\mathrm{Fe}(\mathrm{II})$ \\
\hline & & Spin down & 0.057 & 0.066 & 0.195 & 0.208 & 0.958 & \\
\hline
\end{tabular}




\section{Top View}

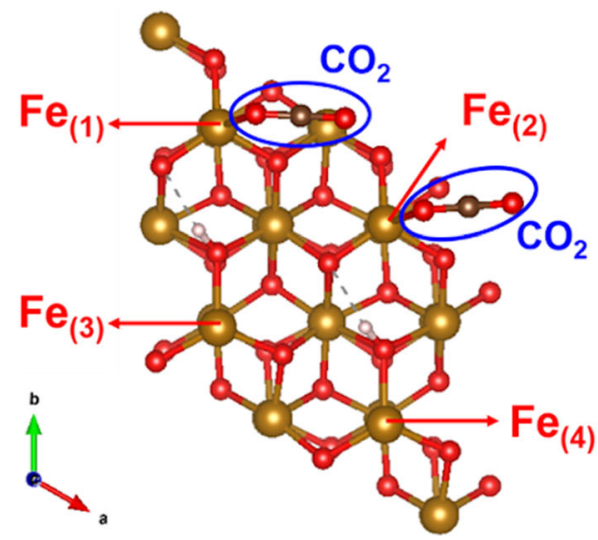

Side View

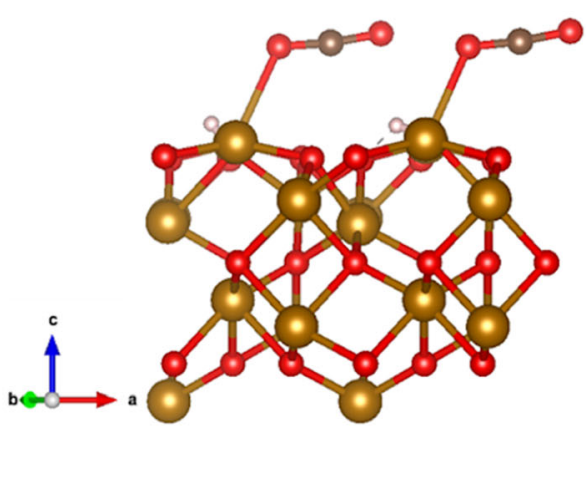

Fig. 1 Top view and side view of the structure after the $\mathrm{C}-\mathrm{C}$ bond breaks on the $\mathrm{Fe}_{2} \mathrm{O}_{3}(0001)$ surface. Brown, Fe; Red, O; and White, $\mathrm{H}$

\section{Experimental Findings}

To establish the formation of humboldtine, the solid phase before and after dissolution was analyzed using SEM-EDS and XRD. The SEM-EDS data were as follows: $14 \mathrm{wt} . \%$ of carbon, 41 wt. $\%$ of iron, and $\sim 1$ wt. $\%$ of other impurities such as aluminum and silicon. The calculated oxygen concentration was 44 wt.\%. The XRD analysis showed that a transformation of the solid phase took place as a result of dissolution (Fig. 2). The XRD pattern was in good agreement with hematite before the dissolution. After dissolution, the pattern showed humboldtine in the $\alpha$ monoclinic phase, a small amount of hematite, and a small fraction of humboldtine in the $\beta$ phase. The XRD peaks were narrow and sharp, indicating a wellformed crystal structure in both cases.

A remarkable change in color was observed between the samples, indicating the formation of humboldtine which has a typical yellow to amber-yellow color (Lide, 1999). The original hematite powder was red whereas the precipitate appeared yellow after the dissolution (Fig. 3a). The SEM images showed very large crystals and chain structures (Fig. 3c,d), in good agreement with the crystallographic structure of humboldtine (Fig. 3b). The DFT results (described above) showed that the iron atoms of the hematite surface can convert to Fe(II) and can precipitate in the presence of oxalates into large quantities of humboldtine crystals given the low solubility $\left(K_{\mathrm{sp}}\right.$ (ferrous oxalate $\left.)=3.2 \cdot 10^{-7}\right)($ Speight et al., 2005) .

\section{SUMMARY AND CONCLUSIONS}

The present study showed that the adsorption of oxalate ion to the surface of hematite and the electron-transfer of Fe(III) to $\mathrm{Fe}(\mathrm{II})$ facilitated the formation of humboldtine. Considering the phase diagram (Lee et al., 2007) and the XRD results, excess amounts of oxalic acid are seen to favor the formation of crystalline humboldtine. The 1:2 molar ratio of Fe $/ \mathrm{C}_{2} \mathrm{O}_{4}$ was required to obtain humboldtine as 1 mole of oxalate was required for the electron transfer of $\mathrm{Fe}(\mathrm{III})$ to $\mathrm{Fe}(\mathrm{II})$, and another 1 mole was needed to form humboldtine. In theory, $\sim 25 \mathrm{~g}$ of humboldtine could be formed using $12 \mathrm{~g}$ of synthetic hematite and $40 \mathrm{~g}$ of oxalic acid dihydrate powder.

If the target was to dissolve hematite without forming humboldtine, this could be achieved by adding the oxalic acid gradually. In addition, humboldtine formation was unlikely to be observed if the reaction scheme was shifted toward carbon dioxide formation.

The most important result of the current study was the discovery of a new pathway to produce large crystals of humboldtine of good quality. The previous method by which

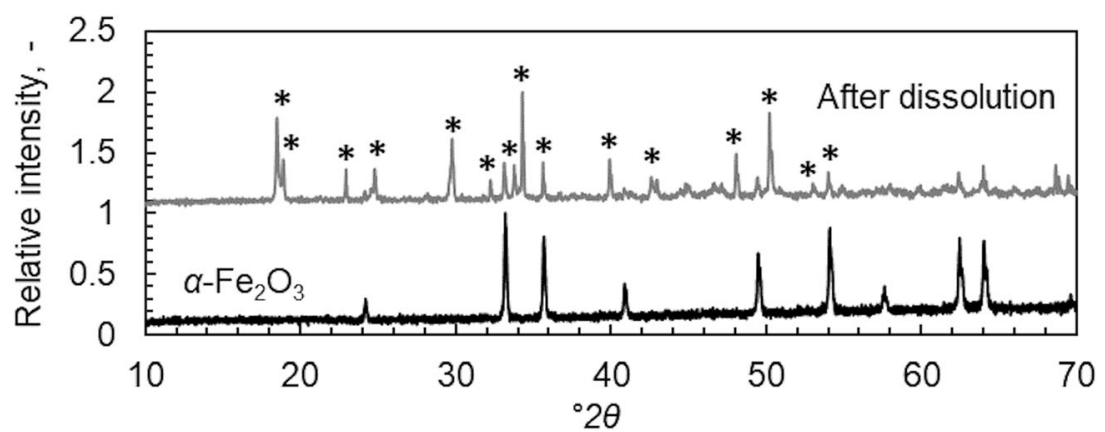

Fig. 2 XRD patterns of solid phases before and after dissolution in $0.33 \mathrm{M}$ oxalic acid at $35^{\circ} \mathrm{C}$. * indicates peaks characteristic of humboldtine $\left(\mathrm{Fe}_{2} \mathrm{O}_{3} \cdot 2 \mathrm{H}_{2} \mathrm{O}\right)$ in the $\alpha$ monoclinic phase 

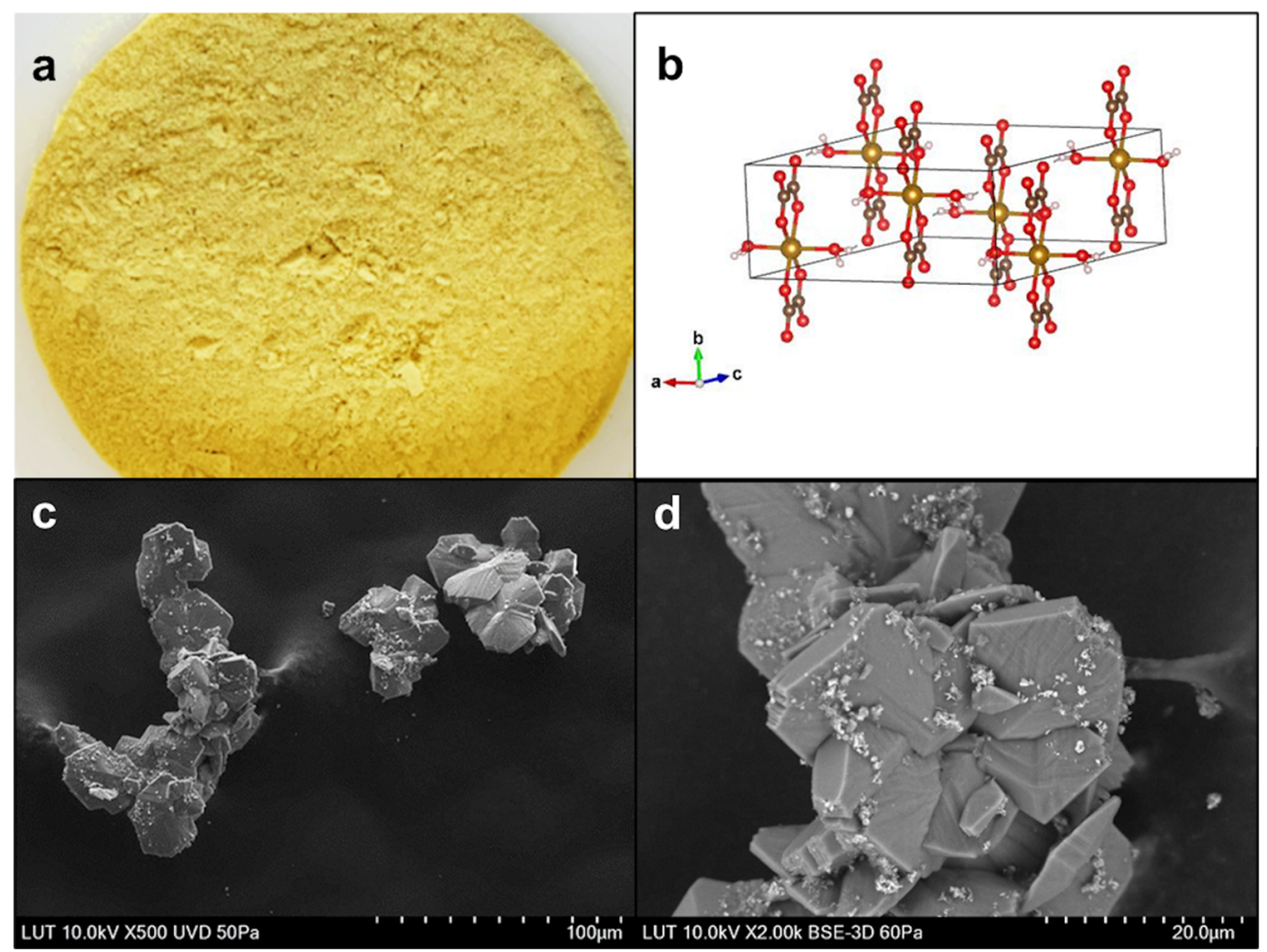

Fig. 3 a Humboldtine powder, b crystal structure of humboldtine, and c, d SEM images at different scales. Brown, Fe; Red, O; Gray, C; and White, $\mathrm{H}$

humboldtine was synthesized involved several steps, whereas the present method requires only mixing of oxalic acid with hematite powder at the appropriate temperature of $35^{\circ} \mathrm{C}$ and for the appropriate experimental time of $<400 \mathrm{~h}$. The XRD analysis showed that the crystal structure was in the monoclinic $\alpha$ phase suitable for applications requiring significant ion mobility (Yamada et al., 2009). The samples could be used for anode material in lithium-ion batteries, therefore (Zhang et al., 2020). Moreover, the DFT calculations provided important atomistic details about the structures after oxalic acid adsorption, and information about the direction and magnitude of the charge-transfer process, which were exhibited by both the Bader charge and oxidation state analysis. Oxalic acid was doubly de-protonated and adsorbed on the $\mathrm{Fe}_{2} \mathrm{O}_{3}$ (0001) surface. The adsorption process alone did not lead to surface reduction. The charge transfer and oxidation state analysis showed that cleavage of the adsorbed oxalate $\mathrm{C}-\mathrm{C}$ bond was key to reducing two surface $\mathrm{Fe}$ (III) to $\mathrm{Fe}$ (II), providing the sites for subsequent reactions of the oxalate to form humboldtine.

\section{ACKNOWLEDGMENTS}

P.V., R.S., and A.H. designed and performed the experiment, and analyzed the data. B.G., P.H.-L.S., and B.B. were responsible for the DFT calculations and the theoretical interpretation of the results. Toni Väkiparta is kindly acknowledged for providing the SEM images. B.G. and P.H.-L.S. acknowledge the computer facility managed by the School of Energy and Environment (SEE) of the City University of Hong Kong. This research was supported by the Ministry of Education and Culture (Finland).

\section{FUNDING}

Open access funding has been provided by LUT University (previously Lappeenranta University of Technology (LUT)). Funding sources are as stated in the Acknowledgments.

\section{Declarations}

\section{Conflict of Interest}

The authors declare that they have no conflict of interest.

Open Access This article is licensed under a Creative Commons Attribution 4.0 International License, which permits use, sharing, adaptation, distribution and reproduction in any medium or format, as long as you give appropriate credit to the original author(s) and the source, provide a link to the Creative Commons licence, and indicate if changes were made. The images or other third party material in this article are included in the article's Creative Commons licence, unless indicated otherwise in a credit line to the material. If material is not included in the article's Creative Commons licence and your intended use is not permitted by statutory regulation or exceeds the permitted use, you will need to obtain permission directly from the copyright holder. To view a copy of this licence, visit http://creativecommons. org/licenses/by/4.0/. 


\section{REFERENCES}

Angermann, A., \& Töpfer, J. (2008). Synthesis of magnetite nanoparticles by thermal decomposition of ferrous oxalate dihydrate. Journal of Materials Science, 43, 5123-5130. https://doi. org/10.1007/s10853-008-2738-3

Applin, D. M., Izawa, M. R. M., Cloutis, E. A., Goltz, D., \& Johnson, J. R. (2015). Oxalate minerals on Mars? Earth and Planetary Science Letters, 420, 127-139. https://doi.org/10.1016/j. eps1.2015.03.034

Aramendia, J., Gomez-Nubla, L., Bellot-Gurlet, L., Castro, K., Arana, G., \& Madariaga, J. M. (2015). Bioimpact on weathering steel surfaces: oxalates formation and the elucidation of their origin. International Biodeterioration \& Biodegradation, 104, 59-66. https://doi.org/10.1016/j.ibiod.2015.05.011

Blake, R., Hessevick, R., Zoltai, T., \& Finger, L. W. (1966). Refinement of the hematite structure. American Mineralogist, 51, 123-129.

Blesa, M. M., Borghi, E. B., Maroto, A.-J. G., \& Regazzoni, A. E. (1984). Adsorption of EDTA and iron EDTA complexes on magnetite and the mechanism of dissolution of magnetite by EDTA. Journal of Colloid and Interface Science, 98, 295-305.

Chang, H.-C., \& Matijevic, E. (1983). Interactions of metal oxides with chelating agents IV. Dissolution of hematite. Journal of Colloid and Interface Science, 92, 479-488.

Cornell, R. M., \& Schindler, P. W. (1987). Photochemical dissolution of goethite in acid/oxalate solution. Clays and Clay Minerals, 35, 347-352.

Dzade, N. Y., Roldan, A., \& de Leeuw, N. H. (2014). A density functional theory study of the adsorption of benzene on hematite $\left(\alpha-\mathrm{Fe}_{2} \mathrm{O}_{3}\right)$ surfaces. Minerals, 4, 89-115. https://doi.org/10.3390 $/ \min 4010089$

Fan, X., Zhang, L., Li, M., Wang, M., Zhou, X., Cheng, R., Zhou, Y., $\&$ Shi, J. (2016). $\alpha$-Ferrous oxalate dihydrate: a simple coordination polymer featuring photocatalytic and photo-initiated Fenton oxidations. Science China Materials, 59, 574-580. https://doi. org/10.1007/s40843-016-5064-y

Gadd, G. M., Bahri-Esfahani, J., Li, Q., Rhee, Y. J., Wei, Z., Fomina, M., \& Liang, X. (2014). Oxalate production by fungi: significance in geomycology, biodeterioration and bioremediation. Fungal Biology Review, 28, 36-55. https://doi.org/10.1016/j. fbr.2014.05.001

Giannozzi, P. \& 32 others (2009). QUANTUM ESPRESSO: a modular and open-source software project for quantum simulations of materials. Journal of Physics: Condensed Matter, 21, 395502. https://doi.org/10.1088/0953-8984/21/39/395502

Green, D. I. (2004). Anthropogenic humboldtine from Cornwall, England. The Geological Curator, 8, 33-36.

Grimme, S. (2006). Semiempirical GGA-type density functional constructed with a long-range dispersion correction. Journal of Computational Chemistry, 27, 1787-1799. https://doi.org/10.1002 /jcc.20495

Henkelman, G., Arnaldsson, A., \& Jónsson, H. A. (2006). Fast and robust algorithm for Bader decomposition of charge density. Computational Materials Science, 36, 354-360. https://doi. org/10.1016/j.commatsci.2005.04.010

Huang, X., Kumar Ramadugu, S., \& Mason, S. E. (2016). Surfacespecific DFT $+U$ approach applied to $\alpha-\mathrm{Fe}_{2} \mathrm{O}_{3}(0001)$. The Journal of Physical Chemistry C, 36, 354-360. https://doi.org/10.1021/acs. jpcc.5b12144

Huskić, I., Pekov, I. V., Krivovichev, S. V., \& Frščić, T. (2016). Minerals with metal-organic framework structures. Science Advances, 2, e1600621. https://doi.org/10.1126/sciadv.1600621

Jensen, S., Tan, K., Feng, L., Li, J., Zhou, H.-C., \& Thonhauser, T. (2020). Porous Ti-MOF-74 framework as a strong-binding nitric oxide scavenger. Journal of the American Chemical Society, 142, 16562-16568. https://doi.org/10.1021/jacs.0c02772

$\mathrm{Ku}, \mathrm{C}$., \& Sit, P. H.-L. (2019). Oxidation-state constrained density functional theory for the study of electron-transfer reactions.
Journal of Chemical Theory and Computation, 15, 4781-4789. https://doi.org/10.1021/acs.jctc.9b00281

Lee, S. O., Tran, T., Park, Y. Y., \& Kim, M. J. (2007). Dissolution of iron oxide using oxalic acid. Hydrometallurgy, 87, 91-99. https://doi.org/10.1016/j.hydromet.2007.02.005

Lide, D. R. (Ed.). (1999). CRC Handbook of Chemistry and Physics (80th ed.). CRC Press.

Majumdar, A., Tse, J. S., Wu, M., \& Yao, Y. (2017). Superconductivity in $\mathrm{FeH}_{5}$. Physical Review B, 96, 201107. https://doi.org/10.1103/PhysRevB.96.201107

Mandal, S. K., \& Banerjee, P. C. (2004). Iron leaching from China clay with oxalic acid: Effect of different physico-chemical parameters. International Journal of Mineral Processing, 74, 263-270. https://doi.org/10.1016/j.minpro.2004.01.004

Müller, H., Bourcet, L., \& Hanfland, M. (2021). Iron(II)oxalate dihydrate - humboldtine: synthesis, spectroscopic and structural properties of a versatile precursor for high pressure Research. Minerals, 11, 113. https://doi.org/10.3390/min11020113

Ogasawara, H., \& Koga, N. (2014). Kinetic modeling for thermal dehydration of ferrous oxalate dihydrate polymorphs: A combined model for induction period-surface reaction-phase boundary reaction. The Journal of Physical Chemistry C, 118, 2401-2412. https://doi.org/10.1021/jp500619q

Panias, D., Taxiarchou, T., Paspaliaris, I., \& Kontopoulos, A. (1996). Mechanisms of dissolution of iron oxides in aqueous oxalic acid solutions. Hydrometallurgy, 42, 257-265. https://doi.org/10.1016 /0304-386X(95)00104-O

Parkinson, G. S. (2016). Iron oxide surfaces. Surface Science Reports, 71, 272-365. https://doi.org/10.1016/j.surfrep.2016.02.001

Perdew, J. P., Burke, K., \& Ernzerhof, M. (1996). Generalized gradient approximation made simple. Physical Review Letterrs, 77, 3865. https://doi.org/10.1103/PhysRevLett.77.3865

Rennert, T., Dietel, J., Heilek, S., Dohrmann, R., \& Mansfeldt, T. (2021). Assesing poorly crystalline and mineral-organic species by extracting $\mathrm{Al}, \mathrm{Fe}, \mathrm{Mn}$, an Si using (citrate-)ascorbate and oxalate. Geoderma, 397, 115095 .

Ricca, C., Timrov, I., Cococcioni, M., Marzari, N., \& Aschauer, U. (2019). Self-consistent site-dependent $\mathrm{DFT}+U$ study of stoichiometric and defective $\mathrm{SrMnO}_{3}$. Physical Review B, 99, 094102. https://doi.org/10.1103/PhysRevB.99.094102

Robinson, G. W. (2004). Mineralogy of Michigan by E.W, Heinrich. Michigan Technical University.

Salmimies, R., Kallas, J., Ekberg, B., Görres, G., Andreassen, J.-P., Beck, R., \& Häkkinen, A. (2013). The scaling and regeneration of the ceramic filter medium used in dewatering of a magnetite concentrate. International Journal of Mineral Processing, 119, 21-26. https://doi.org/10.1016/j.minpro.2012.12.006

Salmimies, R., Vehmaanperä, P., \& Häkkinen, A. (2016). Acidic dissolution of magnetite in mixtures of oxalic and sulfuric acid. Hydrometallurgy, 163, 91-98. https://doi.org/10.1016/j. hydromet.2016.03.011

Schwertmann, U., \& Cornell, R. M. (2003). Iron Oxides in the Laboratory. Weinheim.

Si, Y., Li, M., Zhou, Z., Liu, M., \& Prezhdo, O. (2020). Improved description of hematite surfaces by the SCAN Functional. The Journal of Chemical Physics, 152, 024706. https://doi.org/10.1063 $/ 1.5134951$

Siffert, C., \& Sulzberger, B. (1991). Light-induced dissolution of hematite in the presence of oxalate: a case study. Langmuir, 7, 1627-1634. https://doi.org/10.1021/la00056a014

Sit, P. H.-L., Car, R., Cohen, M. H., \& Selloni, A. (2011). Simple, unambiguous theoretical approach to oxidation state determination via first-principles calculations. Inorganic Chemistry, 50, 10259 10267. https://doi.org/10.1021/ic2013107

Sit, P. H.-L., Cohen, M. H., \& Selloni, A. (2012). Interaction of oxygen and water with the (100) surface of pyrite: Mechanism of sulfur oxidation. The Journal of Physical Chemistry Letters, 3, 2409 2414. https://doi.org/10.1021/jz300996c

Smith, J., Sheridan, C., van Dyk, L., Naik, S., Plint, N., \& Turrer, H. D. G. (2018). Optimal ceramic filtration operating conditions for and 
iron-ore concentrate. Minerals Engineering, 115, 1-3. https://doi. org/10.1016/j.mineng.2017.10.011

Speight, J.G., Lange, N.A., \& Dean, J.A. (Eds.) (2005). Lange's Handbook of Chemistry, sixteenth ed. : McGraw-Hill.

Stone, A. T., \& Morgan, J. J. (1987). Reductive dissolution of metal oxides. In W. Stumm (Ed.), Aquatic Surface Chemistry. John Wiley $\&$ Sons.

Stumm, W., \& Furrer, G. (1987). The dissolution of oxides and aluminum silicates: examples of surface-coordination-controlled kinetics. In W. Stumm (Ed.), Aquatic Surface Chemistry (pp. 197219). John Wiley \& Sons.

Vanderbilt, D. (1990). Soft self-consistent pseudopotentials in a generalized eigenvalue formalism. Physical Review B, 41, 7892 (R). https://doi.org/10.1103/PhysRevB.41.7892

Vehmaanperä, P., Salmimies, R., \& Häkkinen, A. (2021). Thermodynamic and kinetic studies of dissolution of hematite in mixtures of oxalic and sulfuric acid. Mining, Metallurgy \& Exploration, 38, 69-80. https://doi.org/10.1007/s42461-02000308-4

Wang, Z., Fu, H., Zhang, L., Song, W., \& Chen, J. (2017). Ligandpromoted photoreductive dissolution of goethite by atmospheric low-molecular dicaboxylates. The Journal of Physical Chemistry A, 121, 1647-1656. https://doi.org/10.1021/acs.jpca.6b09160

Wang, X., Qiu, R.-Z., Long, Z., Lu, L., Hu, Y., Liu, K.-Z., \& Zhang, P.-C. (2019). Chemical state of $\mathrm{U}$ in $\mathrm{U}-\mathrm{N}-\mathrm{O}$ ternary system from first-principles calculations. The Journal of Physical Chemistry C, 123, 17155-17162. https://doi.org/10.1021/acs.jpcc.9b04288

Wei, H., Huang, K., Wang, D., Zhang, R., Ge, B., Ma, J., Wen, B., Zhang, S., Li, Q., Lei, M., Zhang, C., Irawan, J., Liu, L.-M., \& Wu, H. (2017). Iced photochemical reduction to synthesize atomically dispersed metals by suppressing nanocrystal growth. Nature Communications, 8, 1490. https://doi.org/10.1038/s41467-01701521-4

Yamada, T., Sadakiyo, M., \& Kitagawa, H. (2009). High proton conductivity of one-dimensional ferrous oxalate dihydrate. Journal of the American Chemical Society, 131, 3144-3145. https://doi. org/10.1021/ja808681m

Yao, W., Armstrong, R., Zhou, X., Sougrati, M.-T., Kidkhunthod, P., Tunmee, S., Sun, C., Sattayaporn, S., Lightfoot, P., Ji, B., Jiang, C., Wu, N., Tang, Y., \& Cheng, H.-M. (2019). An oxalate cathode for lithium ion batteries with combined cationic and polyanionic redox. Nature Communications, 10, 3483. https://doi.org/10.1038/s41467019-11077-0

Zhang, K., Li, Y., Wang, Y., Zhao, J., Chen, X., Dai, Y., \& Yao, Y. (2020). Enhanced electrochemical properties of iron oxalate with more stable $\mathrm{Li}^{+}$ions diffusion channels by controlling polymorphic structure. Chemical Engineering Journal, 384, 123281. https://doi. org/10.1016/j.cej.2019.123281

(Received 23 March 2021; revised 14 July 2021; AE: Yuji Arai) 